Paper accepted for publication by Journal of Sound and Vibration, 11 December 2019

DOI: 10.1016/j.jsv.2019.115145

\title{
A mechanism for overcoming the effects of the internal resonances of coil springs on vibration transmissibility
}

\author{
Wenjing Sun ${ }^{a *}$, David Thompson ${ }^{\mathrm{b}}$, Jinsong Zhou $^{\mathrm{a}}$ \\ anstitute of Rail Transit, Tongji University, Shanghai, 201804, People's Republic of China; \\ ${ }^{b}$ Institute of Sound and Vibration Research, University of Southampton, Southampton SO17 \\ IBJ, UK
}

Internal resonances in suspension springs can result in significantly increased vibration transmission at the corresponding natural frequencies. Particularly for the case of metal coil springs used in vehicle suspensions, these internal resonances can be as low as $50 \mathrm{~Hz}$ and can lead to increased structure-borne noise in certain frequency bands. Although, in practice, this can be mitigated to some extent by using rubber pads in series with the coil springs, high vibration transmission in the vicinity of the internal resonance frequencies remains an important issue. In this paper, a mechanism is identified that can overcome the increased vibration transmission due to the internal resonances. This involves the use of a pivoted arm with a pivot bushing that is relatively stiff for translational motion. The quasi-static load is primarily carried by the suspension spring but the dynamic load at higher frequencies is also transmitted through the pivot bushing. By appropriate selection of parameters, in particular the moment of inertia of the pivoted arm and the stiffness of the pivot bushing, it can be arranged that the dynamic loads acting through the spring and the bushing largely cancel each other out at the spring natural frequency. It is shown that this mechanism is contained within common designs of railway vehicle primary suspension. Nevertheless, their design is largely based on their quasi-static behaviour and this principle of dynamic load cancellation has not previously been explained. The dynamic behaviour of different suspension arrangements is compared and the selection of suitable parameter values that can achieve this dynamic load cancellation is explained. Field measurements are also presented which confirm this behaviour.

Keywords: Coil springs; dynamic stiffness; vehicle suspension; vibration transmissibility; internal resonance. 


\section{Introduction}

Metal coil springs are commonly used for isolating the vibration of mechanical structures, including within the suspension systems of railway and automotive vehicles. They provide a high load-bearing capacity for the static support of the vehicle and a sufficiently low stiffness to achieve low frequency isolation for improved ride quality. Compared with rubber springs, they are stable, not suffering from creep deformation, and can be used in a wide range of environments, such as over wide temperature differentials or under corrosive conditions. However, metal coil springs are lightly damped and their internal resonances [1] can degrade the isolator performance at higher frequencies, significantly increasing the force transmissibility and structure-borne noise [2]. This degradation can be as high as 20-30 dB in the force transmissibility at the internal resonance frequencies and 10-20 dB in the overall noise radiation [3]. These dynamic effects in resilient elements are also often referred to as wave effects $[1,4]$.

Ungar and Dietrich [5] discussed the standing waves in resilient elements in relation to vibration isolation. They noted that the wave effects are more important in heavier and larger isolators. Yan et al. [6] studied the isolating performance of a helical spring as a distributed isolator and compared the results of theoretical analysis and experiments. They showed that the transmissibility at high frequencies contains many peaks not found for a massless isolator. Douville et al. [7] presented a methodology to identify structure-borne noise transmission paths for an automotive suspension assembly. Their results showed that the most significant transfer path was in the vertical direction through the suspension; peaks were found in the transfer functions corresponding to natural frequencies of the coil springs. Dylejko et al. [8] studied the effects of internal resonances in machinery mounts on the noise radiation of ships. In other studies it has been shown that internal resonances of coil springs may also result in large amplitude vibration of the spring itself, leading to fatigue failure $[9,10]$.

To suppress the influence of internal resonances, various techniques have been considered. Du et al. [3] used passive and hybrid active-passive dynamic vibration absorbers to control the internal resonances in rubber vibration isolators. Yan et al. [11] used an active control method to suppress the effects of internal resonances on the vibration transmissibility from coil springs. Dylejko and MacGillivray [12] introduced a transmission absorber, based on the concept of an inerter, to suppress internal resonances with inertial forces. Michalczyk [13] applied a highly-damped coating to the end coils of a coil spring to reduce the amplification due to resonance. 
Many rail vehicles use metal coil springs in their suspension system. Rail vehicles running on bogies usually have two levels of suspension, intended to isolate the vehicle structure from the vibration generated at the wheel/rail contact. The secondary suspension, between the bogie and the car body, isolates the car body from vibration above $1-2 \mathrm{~Hz}$, whereas the primary suspension, between the wheelsets and the bogie frame, isolates the bogie from wheel/rail vibration above about $10 \mathrm{~Hz}$. At higher frequencies, flexible modes of the whole car body, as well as local vibration modes of parts of the car body can have a significant influence on passenger comfort [14] and can also generate structure-borne noise [15]. Coil springs are commonly used in the primary suspension for isolating vibration in this frequency range. Usually, these are installed as two concentric springs in series with a rubber pad; the latter is intended to avoid excessive stiffening at the internal resonances [10]. Also for freight vehicles, various different primary suspension designs are used, many of which also contain coil springs [16].

Normally, in vehicle dynamics studies the suspension springs are modelled as simple frequency-independent stiffness elements [17]. This is an acceptable approximation at very low frequencies, but as the influence of the internal resonances of the spring grows at higher frequencies, this assumption becomes invalid. The first internal resonances of coil springs in the primary suspension of rail vehicles can be as low as $50 \mathrm{~Hz}$. Thus, it can be expected that the dynamic stiffening effect will influence the structural vibration and noise transmission. Sun et al. [18] built a vertical dynamic model of a high speed railway vehicle with a simplified model of the primary suspension that included a dynamic model of the coil springs. The results showed that dynamic stiffening effects increased the vibration of the bogie and car body above about $50 \mathrm{~Hz}$.

Two examples of primary suspensions from metro vehicles are shown in Figure 1. Such designs involve the use of a pivoted arm with a relatively stiff pivot bushing [19] (at the left of the photographs). In the arrangement in Figure 1(a) the coil springs are located directly above the axle box. In Figure 1(b), however, the hydraulic damper, and also the springs, are located between the pivoted arm and the bogie frame, on the opposite side of the axle box to the pivot. Due to the lever-arm effect, the coil springs in Figure 1(b) take a smaller static load and can have a lower static stiffness than those in Figure 1(a). These radial arm designs allow more compact bogie frames as the spring can sit alongside the wheel bearing rather than being mounted directly above it. The longitudinal and lateral stiffnesses of the pivot bushing are considered more critical in their design and have been studied for better curving performance 
[20]. In contrast, the vertical vibration isolation performance of primary suspension structures with a radial arm has not been investigated in detail.

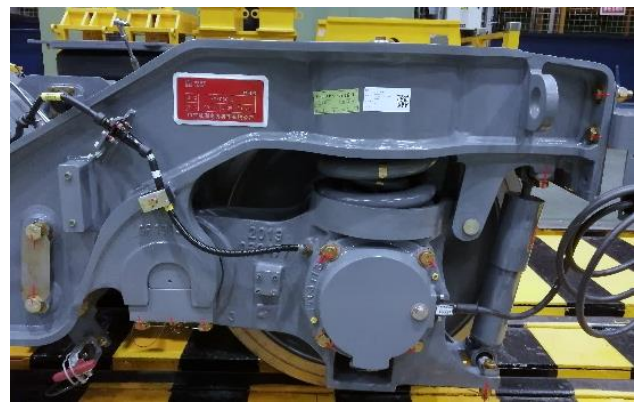

(a)

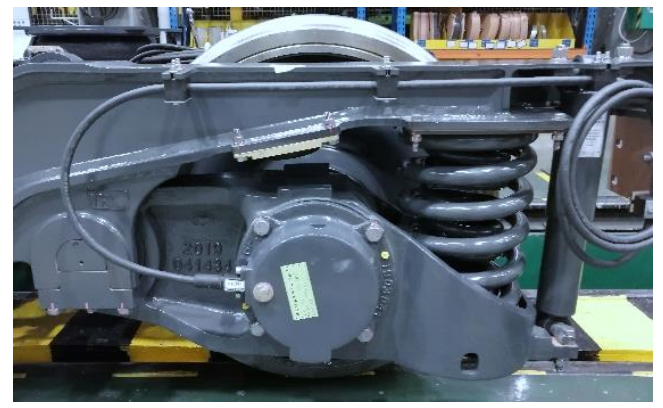

(b)

Figure 1. Examples of different designs of metro vehicle primary suspension with radial arm. (a) Centrally placed coil spring set; (b) side-placed coil spring set.

In the present paper, motivated by these radial arm suspension designs of rail vehicles, a pivot arm mechanism is investigated to determine its potential for controlling the dynamic amplification associated with coil spring internal resonances. In Section 2 the transmissibility of such pivot arm arrangements is investigated. The dynamic amplification due to the spring internal resonances is introduced into this model in Section 3 by using a simple model of a distributed parameter isolator and the effects of various parameters are investigated. In Section 4 the particular case of the rail vehicle suspension design is discussed and the effect of the coil springs and the pivot arm on the vehicle and track dynamic response is investigated.

\section{Comparison of different arrangements for suspension system}

\subsection{Model}

Three different suspension arrangements are shown schematically in Figure 2, each of which is intended to provide isolation from a base input $z_{1}$. In the first arrangement, in Figure 2(a), the suspension spring of stiffness $k$ and viscous damper $c$ are mounted directly above the base input. The spring is considered as massless in this section and for simplicity the damper is represented by a constant viscous damping coefficient. In the second arrangement, in Figure 2(b), a pivoted arm is introduced, similar to the arrangement in Figure 1(a). In the third arrangement, in Figure 2(c), the spring is located on the pivoted arm at a distance $l_{s}$ to one side of the base input point, similar to the arrangement in Figure 1(b). In both of these latter arrangements a flexible bushing is included at the pivot, with vertical stiffness $k_{p}$; it is assumed that the rotational stiffness of the pivot is negligible. In each case the suspension is supporting 
a mass, $m_{2}$. The base input point has a mass $m_{1}$ and the pivot arm, where present, has a moment of inertia $I$ about the base input point. The distances $l_{s}, l_{d}$ and $l_{p}$ represent the lateral distances from the input point to the spring, damper and pivot point respectively. The suspended mass, $m_{2}$, is assumed not to rotate. In practice, this could be achieved by mounting two pivot arms symmetrically; such an arrangement is found for a railway bogie supported by two wheelsets.

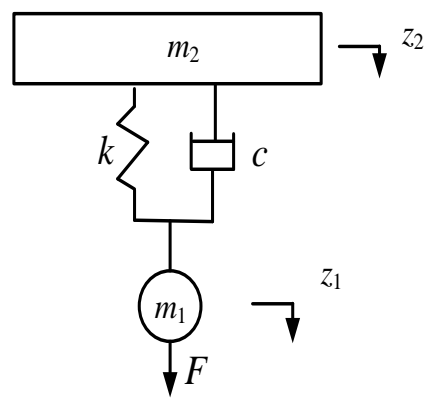

(a)

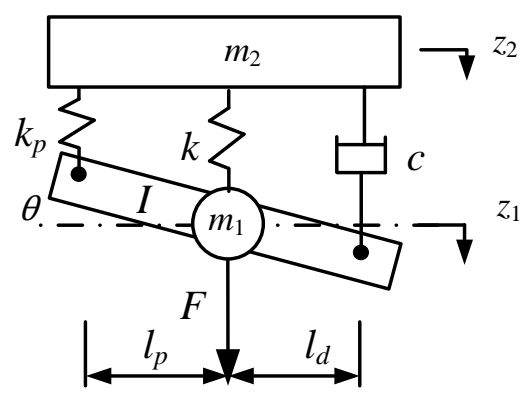

(b)

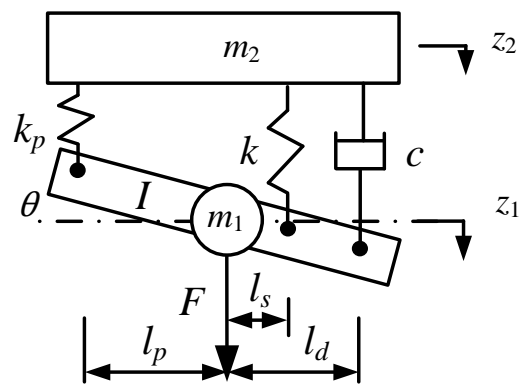

(c)

Figure 2. Different suspension arrangements. (a) Centrally placed spring without pivot arm; (b) centrally placed spring with pivot arm; (c) side-placed spring with pivot arm.

If a harmonic force of amplitude $F$ at circular frequency $\omega$ is applied to the mass $m_{1}$ (with implied time dependence $\mathrm{e}^{\mathrm{i} \omega t}$ ), the equations of motion for these three arrangements can be written as

$$
\left(-\omega^{2} \mathbf{M}+\mathrm{i} \omega \mathbf{C}+\mathbf{K}\right) \mathbf{z}=\mathbf{F}
$$

where, for the system in Figure 2(a), $\mathbf{z}=\left[\begin{array}{ll}z_{2} & z_{1}\end{array}\right]^{\mathrm{T}}$, and

$$
\mathbf{M}=\left[\begin{array}{cc}
m_{2} & \\
& m_{1}
\end{array}\right] ; \quad \mathbf{C}=\left[\begin{array}{cc}
c & -c \\
-c & c
\end{array}\right] ; \quad \mathbf{K}=\left[\begin{array}{cc}
k & -k \\
-k & k
\end{array}\right]
$$

whereas for the system in Figure 2(b) and Figure 2(c), $\mathbf{z}=\left[\begin{array}{lll}z_{2} & z_{1} & \theta\end{array}\right]^{\mathrm{T}}$, and 
$\mathbf{M}=\left[\begin{array}{cccc}m_{2} & & \\ & m_{1} & \\ & & I\end{array}\right] ; \quad \mathbf{C}=\left[\begin{array}{ccc}c & -c & -c l_{d} \\ -c & c & c l_{d} \\ -c l_{d} & c l_{d} & c l_{d}^{2}\end{array}\right] ; \quad \mathbf{K}=\left[\begin{array}{ccc}k+k_{p} & -k-k_{p} & -k l_{s}+k_{p} l_{p} \\ -k-k_{p} & k+k_{p} & k l_{s}-k_{p} l_{p} \\ -k l_{s}+k_{p} l_{p} & k l_{s}-k_{p} l_{p} & k l_{s}^{2}+k_{p} l_{p}^{2}\end{array}\right]$

where $l_{\mathrm{s}}$ is zero for Figure 2(b). The force vector $\mathbf{F}$ is set to have the component corresponding to $z_{1}$ equal to $F$ and other components equal to 0 . To find the displacement transmissibility, the ratio of the responses $z_{2}$ and $z_{1}$ is formed, which is then independent of $F$. To obtain the force transmissibility, the force in each component should be determined from the relative displacement (or velocity) and the corresponding spring or damper coefficient.

\subsection{Results for constant spring stiffness}

Example calculation results are presented in this section for the parameters listed in Table 1, which are chosen to be typical of a rail vehicle suspension without representing any particular vehicle. Three models are considered, corresponding to the cases shown in Figure 2. In the second and third models, for convenience the offset distance of the spring and damper are selected to be equal. Moreover, in the third model the stiffness of the suspension spring and the damping coefficient of the damper are reduced to $30 \%$ of their original values to allow for their offset position while retaining the same overall static stiffness (and corresponding damping). Internal damping of the spring and pivot bushing is introduced by making their stiffness complex with the form $k(1+\mathrm{i} \eta)$ where $\eta$ is the corresponding loss factor (this is included in the stiffness matrix, not the damping matrix).

Table 1. Initial parameters used for the three models

\begin{tabular}{lcccc}
\hline \multicolumn{1}{c}{ Parameters } & & Model 1 & Model 2 & Model 3 \\
\hline Suspended mass & $m_{2}$ & $600 \mathrm{~kg}$ & $600 \mathrm{~kg}$ & $600 \mathrm{~kg}$ \\
Unsprung mass & $m_{1}$ & $1000 \mathrm{~kg}$ & $1000 \mathrm{~kg}$ & $1000 \mathrm{~kg}$ \\
Moment of inertia of pivot arm & $I$ & - & $10 \mathrm{kgm}$ & $10 \mathrm{kgm}$ \\
Static stiffness of suspension spring & $k$ & $1.0 \mathrm{MN} / \mathrm{m}$ & $1.0 \mathrm{MN} / \mathrm{m}$ & $0.3 \mathrm{MN} / \mathrm{m}$ \\
Damping loss factor of suspension spring & $\eta$ & 0.01 & 0.01 & 0.01 \\
First fixed-fixed natural frequency & $f_{1}$ & $95 \mathrm{~Hz}$ & $95 \mathrm{~Hz}$ & $50 \mathrm{~Hz}$ \\
Damping coefficient of damper & $c$ & $10 \mathrm{kNs} / \mathrm{m}$ & $10 \mathrm{kNs} / \mathrm{m}$ & $3 \mathrm{kNs} / \mathrm{m}$ \\
Vertical stiffness of pivot bushing & $k_{p}$ & - & $20 \mathrm{MN} / \mathrm{m}$ & $20 \mathrm{MN} / \mathrm{m}$ \\
Damping loss factor of pivot bushing & $\eta_{p}$ & - & 0.25 & 0.25 \\
Distance from input point to pivot bushing & $l_{p}$ & 0 & $0.4 \mathrm{~m}$ & $0.4 \mathrm{~m}$ \\
Distance from input point to damper & $l_{d}$ & 0 & 0 & $0.33 \mathrm{~m}$ \\
Distance from input point to spring & $l_{s}$ & 0 & 0 & $0.33 \mathrm{~m}$ \\
\hline
\end{tabular}

For each of these arrangements, Figure 3(a) shows the displacement transmissibility from the unsprung mass $m_{1}$ to the suspended mass $m_{2}$ and Figure 3(b) shows the transmissibility 
to the pivot point (the bottom of the spring $k_{p}$ ). In each case the fundamental suspension resonance, at which the transmissibility has a peak, occurs at about $6 \mathrm{~Hz}$. For model 1 this is given by $\frac{1}{2 \pi} \sqrt{k / m_{2}}$ whereas for model 2 this expression holds only approximately due to the influence of the pivot arm moment of inertia. For model 3 the reduced value of stiffness $k$ has been chosen to ensure that this resonance occurs at the same frequency as model 2. Comparing Figures 3(a) and (b), for models 2 and 3 the pivot location has the same vibration amplitude as the suspended mass below $20 \mathrm{~Hz}$. However, there is also a second resonance caused by the rotation of the pivot arm, which occurs at about $95 \mathrm{~Hz}$ for the current parameters. This can be found approximately from $\frac{1}{2 \pi} \sqrt{k_{p} l_{p}^{2} / I}$. It is seen in Figure 3 as a peak in the displacement of the upper mass as well as the pivot location. At this frequency the transmissibility to the suspended mass is more than a factor of 10 greater than for the simple arrangement without the pivot arm.
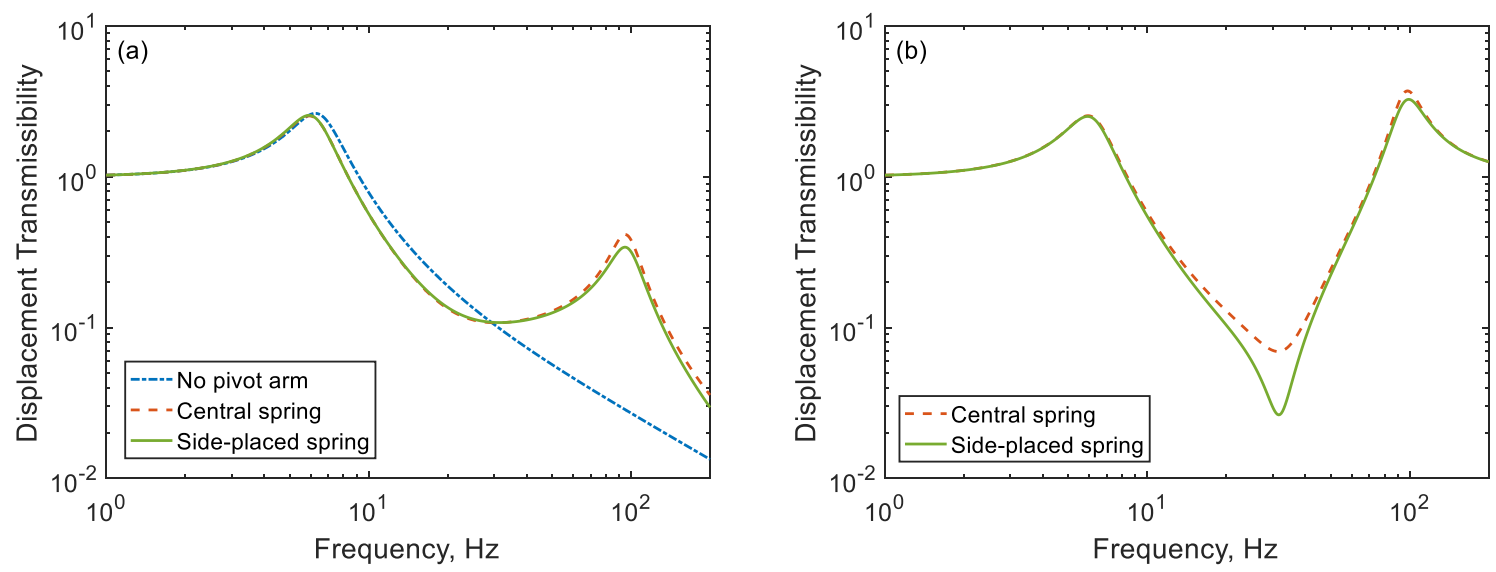

Figure 3. Displacement transmissibility from the input point to (a) suspended mass; (b) pivot. Results for static spring stiffness.

Figure 4 presents the ratios of the forces transmitted through the spring, damper and pivot bushing to the applied force $F$, as well as the total force transmissibility. At low frequencies this is less than unity due to the influence of the unsprung mass $m_{1}$ (it is given by $\left.m_{2} /\left(m_{1}+m_{2}\right)\right)$. For the conventional arrangement without the pivot arm, as is well known, the force is mainly transmitted through the spring at low frequencies, whereas the damper force, which is proportional to velocity, becomes larger at high frequencies. However, for the arrangements with the pivot arm, the force transmitted through the pivot bushing becomes the largest component above about $20 \mathrm{~Hz}$ and increases to a peak at $95 \mathrm{~Hz}$. Moreover, this force is 
out of phase with the force transmitted through the spring, at all frequencies for the central spring and above $20 \mathrm{~Hz}$ for the side-placed spring.
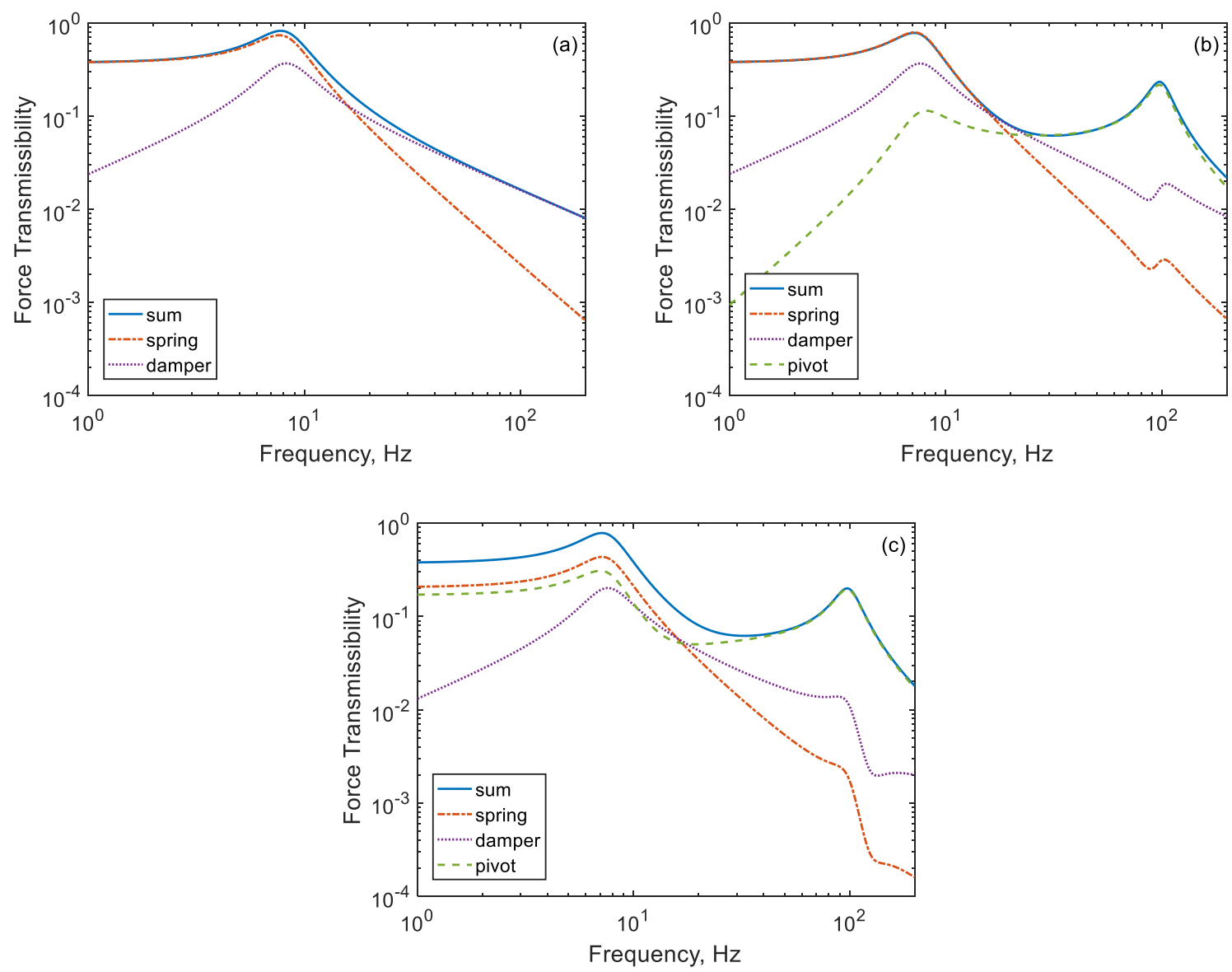

Figure 4. Force transmissibility from the input force to the force transmitted by each component. (a) No pivot arm; (b) central spring; (c) side-placed spring. Results for static spring stiffness.

\section{Inclusion of spring with distributed mass}

\subsection{Model for spring with distributed mass}

To include the dynamic effects of a coil spring, it is possible to use analytical methods [21] or numerical approaches such as the finite element method [10, 22]. However, for simplicity, in this section a simple unidirectional model of an isolator with distributed mass is used [23]. This has been shown to give acceptable results for a coil spring [6].

The dynamic stiffness matrix of the spring (at each frequency) can be expressed in the form:

$$
\left[\begin{array}{cc}
k_{22} & -k_{21} \\
-k_{12} & k_{11}
\end{array}\right]\left[\begin{array}{l}
z_{2} \\
z_{1}
\end{array}\right]=\left[\begin{array}{l}
F_{2} \\
F_{1}
\end{array}\right]
$$


where $z_{2}$ is the displacement at the top of the spring; $z_{1}$ is the displacement at the bottom of the spring, and $F_{1}$ and $F_{2}$ are the forces acting at each end. This dynamic stiffness matrix is introduced into the models of Section 2.1 by replacing the terms $k$ in the matrix $\mathbf{K}$ in Equations (2) and (3) by the corresponding terms. Assuming an equivalent elastic modulus $E$, density $\rho$, cross-sectional area $A$ and height $h$, the point and transfer stiffnesses are given by [23]

$$
k_{11}=k_{22}=\frac{E A \kappa}{\tan (\kappa h)} ; k_{12}=k_{21}=\frac{E A \kappa}{\sin (\kappa h)}
$$

where $\kappa=\omega \sqrt{\rho / E}$ is the wavenumber of compressional waves in the spring. Damping can be included by making $E$ complex with the form $E(1+i \eta)$, where $\eta$ is the damping loss factor. At low frequencies, both these stiffnesses tend to the static stiffness $k=E A / h$. To select the parameters it is sufficient to know the static stiffness $k$, the damping loss factor and the first fixed-fixed natural frequency $f_{1}$, at which $\kappa h=\pi$, giving

$$
k_{11}=\frac{k(1+\mathrm{i} \eta) \beta}{\tan (\beta)} ; k_{12}=\frac{k(1+\mathrm{i} \eta) \beta}{\sin (\beta)} \text { where } \beta=\frac{\pi f}{f_{1}(1+\mathrm{i} \eta)^{1 / 2}}
$$

For the parameters listed in Table 1, the dynamic stiffnesses of the two different springs are shown in Figure 5. As indicated in Table 1 the first fixed-fixed natural frequency for the central spring is selected to be $95 \mathrm{~Hz}$ and that for the side-placed spring is $50 \mathrm{~Hz}$. The reason for selecting these frequencies will become evident below. At these frequencies both point and transfer stiffnesses have a peak, which for the assumed value of damping loss factor (0.01) is more than 100 times the static stiffness. This value of loss factor is greater than the actual damping of a metal coil spring but is chosen to approximate the effect of the rubber pad seen in [10].
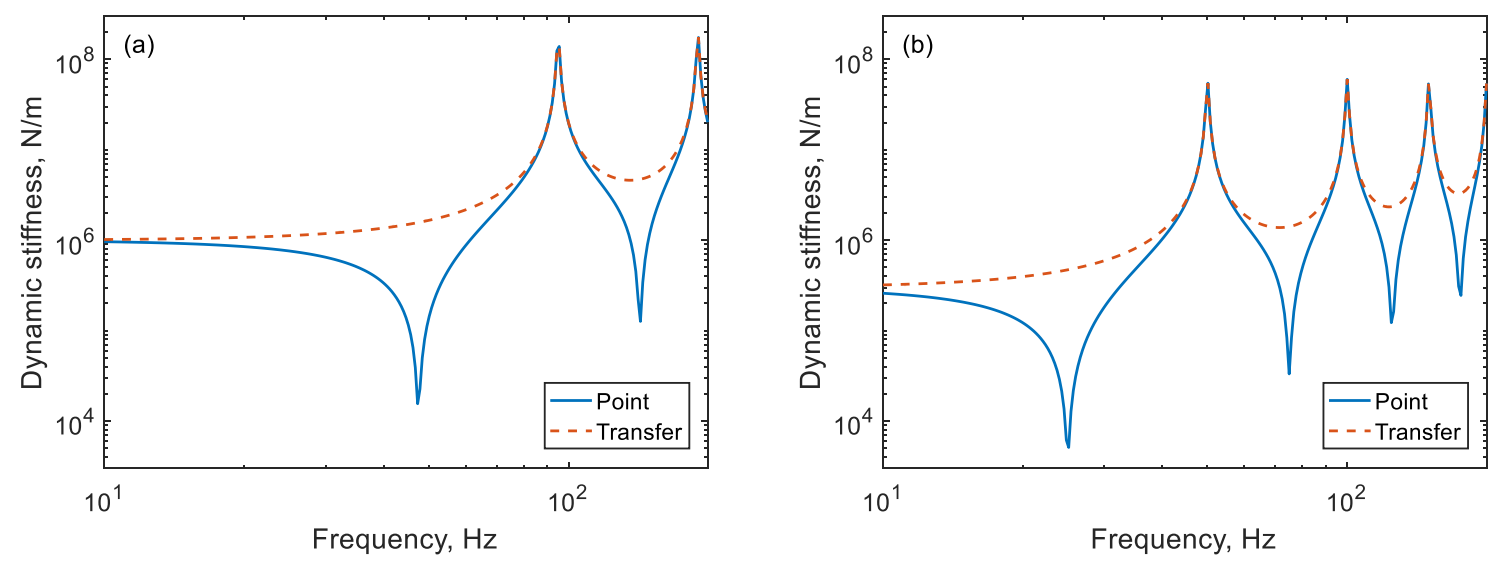

Figure 5. Dynamic stiffness of simple spring model for (a) central spring (models 1 and 2); (b) side-placed spring (model 3). 


\subsection{Results for spring with frequency-dependent stiffness}

Figure 6 shows the displacement transmissibility obtained when the dynamic spring model is included in the three suspension arrangements. Compared with the results for the static stiffness in Figure 3, a large amplification is seen for model 1 with no pivot arm, in this case at $95 \mathrm{~Hz}$. However, for the two cases with the pivot arm, the displacement is similar to that in Figure 3 and no large amplification is seen. Particularly for the case with the side-placed spring, model 3, there is actually a dip in the response at the spring natural frequency of $50 \mathrm{~Hz}$. For the central spring case, there is no peak in Figure 6 at the spring resonance, but also no dip.

To help explain these results, Figure 7 shows the transmitted forces for models 1 and 3 . In both cases, the spring force has a sharp peak at the corresponding spring natural frequencies. However, for the case of the side-placed spring, the force transmitted through the pivot bushing also has a sharp peak at this frequency and, as noted previously, this is out of phase with the force transmitted through the spring. Consequently, the total force acting on the suspended mass is not amplified by the spring resonance and even has a dip at the spring natural frequency for these parameter values. A similar phenomenon occurs for the central spring of model 2 (not shown).

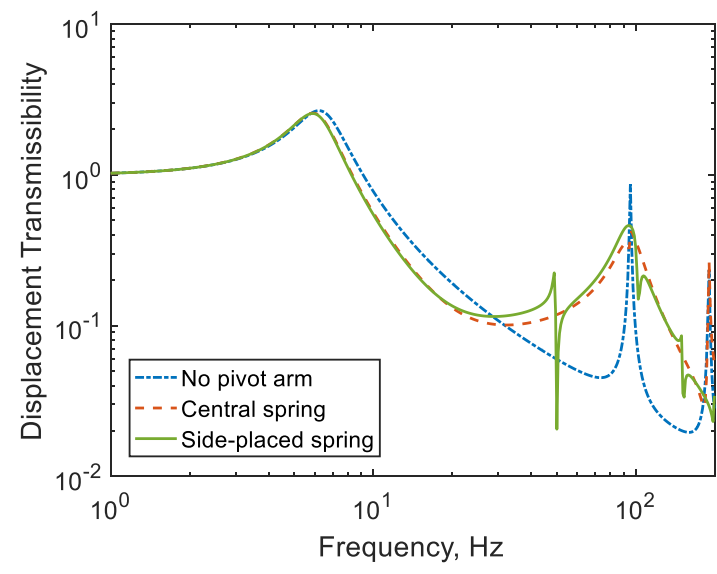

Figure 6. Displacement transmissibility from the input point to the suspended mass for dynamic spring stiffness. 

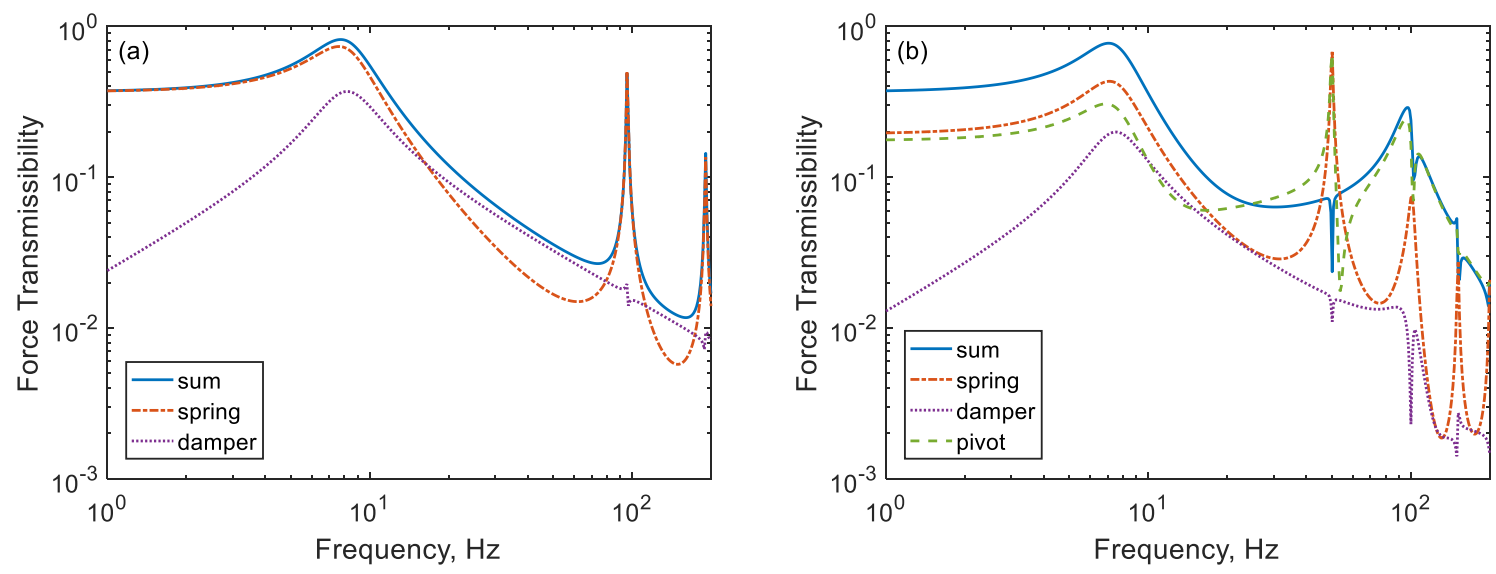

Figure 7. Force transmissibility from the input force to the force transmitted by each component. (a) No pivot arm (model 1); (b) side-placed spring (model 3). Results for dynamic spring stiffness.

\subsection{Parametric study}

The parameter values in Table 1 have been chosen to show maximum cancellation at the spring natural frequencies. Practical railway vehicles can vary, with different values of pivot stiffness and pivot arms with different moments of inertia. The dependence on each parameter will be illustrated in this section by varying each one separately within a range that is wide enough to see clear trends, while not being unrealistic. Figure $8(a, b)$ shows the effect of varying the pivot bushing stiffness of the central and side-placed models (models 2 and 3 ) with static spring stiffness. As expected, the rotational natural frequency shifts in proportion to $k_{p}{ }^{1 / 2}$. Figure 8(c,d) shows the effect of including the dynamic spring model for these two cases. For the central spring, in Figure 8(c), there are peaks at the spring resonance for larger or smaller values of $k_{p}$ than previously. For the side-placed spring in Figure 8(d), although there are dips in the results for 6.3 and $63 \mathrm{MN} / \mathrm{m}$, these are not at the spring natural frequency whereas for $20 \mathrm{MN} / \mathrm{m}$ the dip is close to the spring resonance. 

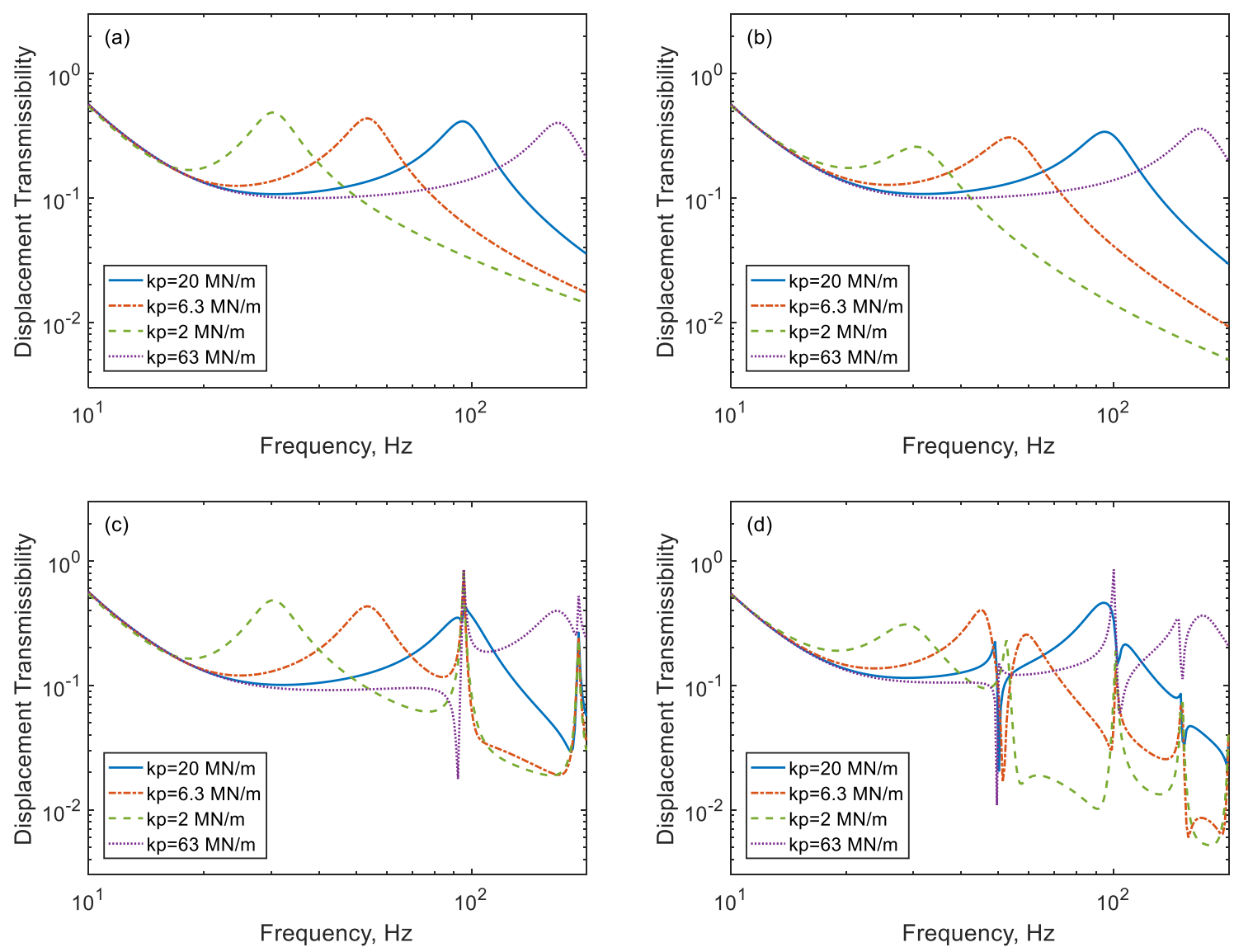

Figure 8. Effect of pivot bushing stiffness on displacement transmissibility from the input point to the suspended mass. (a) Central spring, static spring stiffness; (b) side-placed spring, static spring stiffness; (c) central spring, dynamic spring stiffness; (d) side-placed spring, dynamic spring stiffness.

Figure 9 shows the effect of varying the pivot arm moment of inertia. The rotational natural frequency shifts in proportion to $I^{1 / 2}$, but the transmissibility amplitude also changes. Figure 9(c) shows the effect of including the dynamic spring model for the central spring. There are peaks at the spring resonance for larger or smaller values of $I$. For the side-placed spring, in Figure 9(d), there is also a dip for $30 \mathrm{kgm}^{2}$ but the value at the dip is lowest for $10 \mathrm{kgm}^{2}$. 

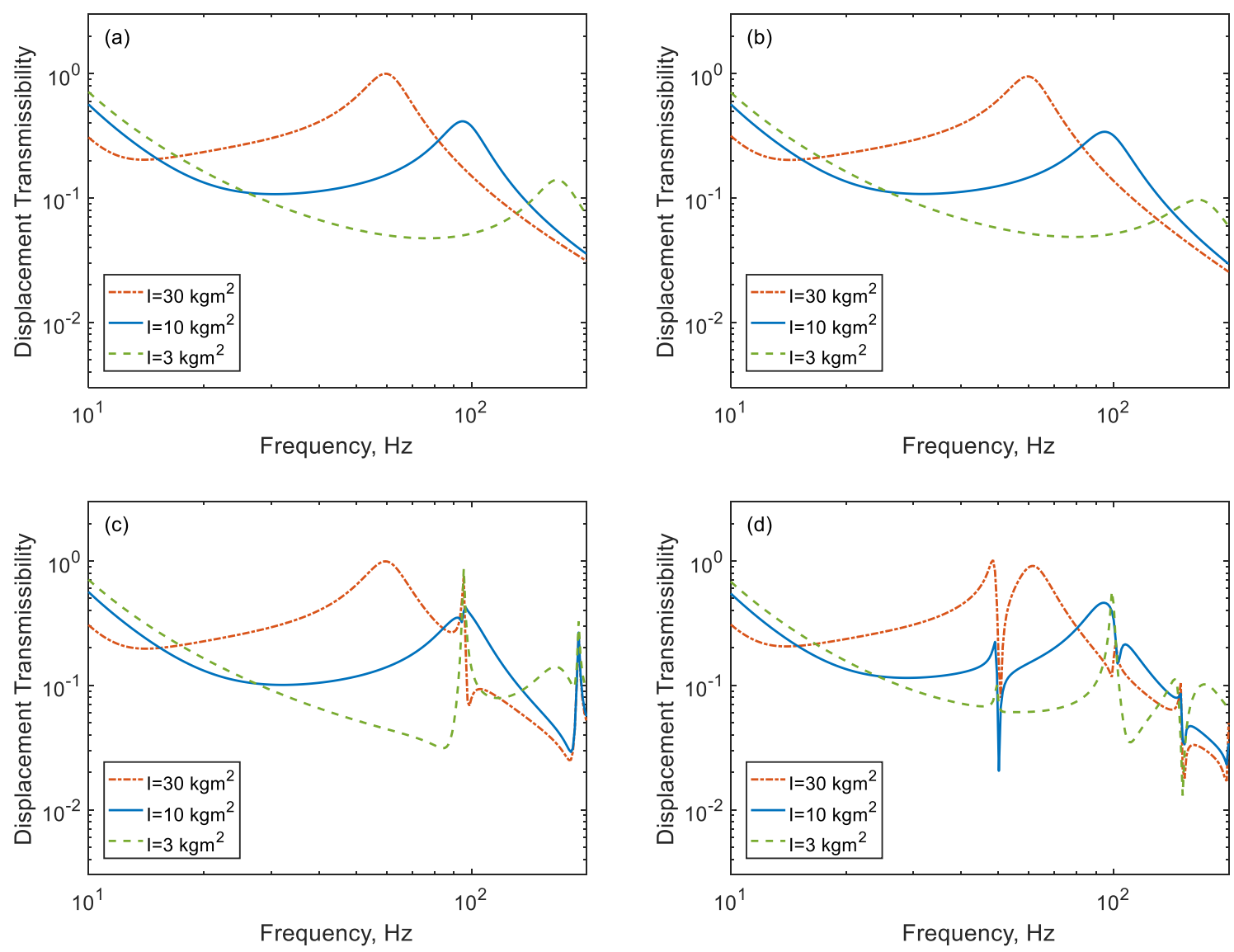

Figure 9. Effect of pivot arm moment of inertia on displacement transmissibility from the input point to the suspended mass. (a) Central spring, static spring stiffness; (b) side-placed spring, static spring stiffness; (c) central spring, dynamic spring stiffness; (d) side-placed spring, dynamic spring stiffness.

To show the effects of various parameters on the dynamic amplification at the spring natural frequency, Figure 10 shows the ratio of the transmissibility with the dynamic spring stiffness to that with the static spring stiffness. The results in Figure 10(a,b) are determined at $95 \mathrm{~Hz}$ for the central spring or at $50 \mathrm{~Hz}$ for the side-placed spring. They confirm that the chosen values of pivot stiffness and pivot arm moment of inertia correspond closely to minima in the dynamic amplification at the spring natural frequency, as seen in Figures 8 and 9. Figure 10(c) shows the effect of varying the spring natural frequency on this ratio. Again, the minimum values occur close to the chosen values of $95 \mathrm{~Hz}$ for the central spring and $50 \mathrm{~Hz}$ for the sideplaced spring. 

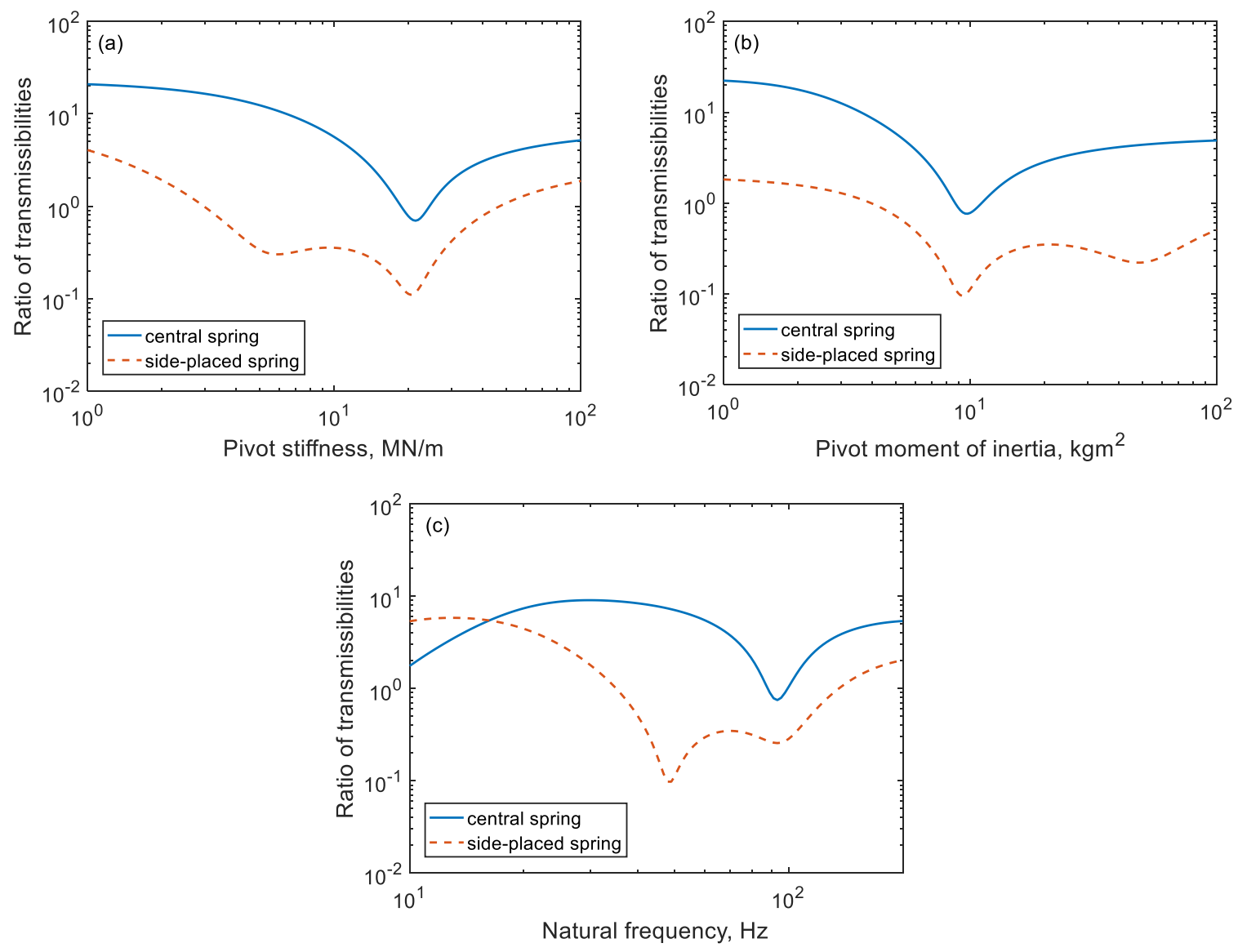

Figure 10. Ratio of transmissibility with dynamic spring stiffness to that with static spring stiffness at the corresponding spring resonance frequencies $(95 \mathrm{~Hz}$ for central spring, $50 \mathrm{~Hz}$ for side-placed spring). (a) Plotted against pivot stiffness; (b) plotted against pivot arm moment of inertia; (c) plotted against spring natural frequency.

Comparing the results for the different models in Figure 6, it can be noted that, although the pivot arm arrangement overcomes the high transmissibility at the spring resonance, it leads to a higher transmissibility than the simple arrangement of model 1 at other frequencies. The overall isolation is therefore not necessarily improved by the pivot arrangement. The relative importance of these other frequency components depends on the application, so it is difficult to give a general conclusion. For example, in Figure $9(\mathrm{c}, \mathrm{d})$ it can be seen that a reduced moment of inertia gives a lower transmissibility over a broad frequency range even though there is a peak in the amplitude at the spring resonance.

Additionally it should be noted that, although the transmissibility at the spring natural frequency is improved by the pivot arm, the stresses in the spring will not be significantly affected as the force transmitted through the spring remains high (see Figure 7). 


\section{Application to rail vehicles}

\subsection{Vertical vehicle-track coupled dynamic model}

In this section the dynamic behaviour of metro rail vehicles containing a radial arm suspension is studied to show how the phenomena described in the previous section occur in practice. A two-dimensional vehicle model is considered, with four wheelsets coupled to the track and excited by the track unevenness; only motions symmetric about the track centreline are considered, with only motion in a vertical plane included. Flexibility of wheelset, bogie frame and car body is neglected. This model is shown schematically in Figure 11(a). Two variants are considered, as shown in Figure 11(b), one with the primary suspension spring set directly above the axlebox and the other with a side-placed spring set (see also Figure 1). Figure 11(c) shows details of the primary suspension arrangement schematically. The vehicle model has a total of 14 degrees of freedom, including the vertical displacement and pitch of the car body, the two bogie frames and the axle boxes/radial arms. Both models include the coil spring set with rubber pad, the rubber bushing at the radial arm pivot point and the hydraulic damper. The damper is mounted in series with a spring representing the rubber bushings installed at its ends. Although more complex models could be considered for the hydraulic damper [17], it has already been shown in Figure 4 that the force from the damper is less than that from the other components above $20 \mathrm{~Hz}$. The model used for the damper is therefore expected to have little influence on results of interest around the internal resonance frequencies of the coil springs. The model includes the dynamic stiffness matrix of the coil spring set (two concentric coil springs with rubber pad) which has been calculated using a finite element model. The corresponding properties of the coil springs are listed in Table 2. The first fixed-fixed natural frequencies of the side-placed spring set are $51.9 \mathrm{~Hz}$ and $58.2 \mathrm{~Hz}$ [10], corresponding to modes of the outer and inner springs, whereas for the central spring set these are found around 80.8 and $97.0 \mathrm{~Hz}$. Models representing the coil springs only by their static stiffness are also considered for comparison.

The track is modelled by a continuously supported rail, as shown in Figure 11(a). The rail is represented by an infinite Timoshenko beam; damping of the rail is considered by introducing a loss factor $\eta_{r}=0.01$ into the Young's modulus and shear modulus. The foundation consists of a single-layer fastener system on a concrete slab, which is a typical track form used for metro systems. The slab is assumed to be rigid. The wheel and track models are coupled together in terms of their Green's functions using the approach described in [24]. 
The parameters of the vehicle and track used in the simulations are listed in Table 3. The masses are given in the table in terms of the whole vehicle, although in the following only the responses at a single rail are considered. The suspension parameters are given per component. The mass, stiffness and damping matrices are assembled and then, applying a unit amplitude force at each of the four wheels in turn, the point and transfer mobilities (velocities for a unit force) of the wheels can be found. The excitation is given by the track unevenness (or roughness), which is introduced between the wheels and the rail. Each wheel/rail contact is assumed to be excited by the same unevenness spectrum apart from a phase lag introduced by the time delay between the different wheels passing over a point on the track [24]. The AAR class 4 unevenness spectrum is assumed [25].

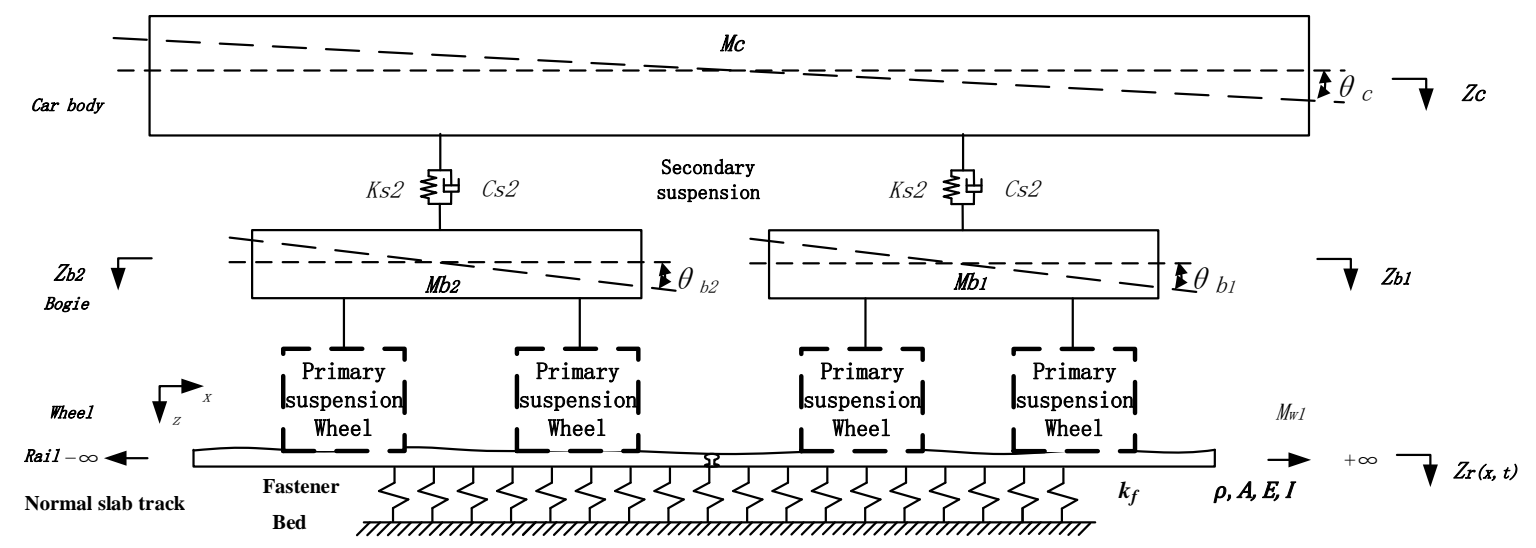

(a)

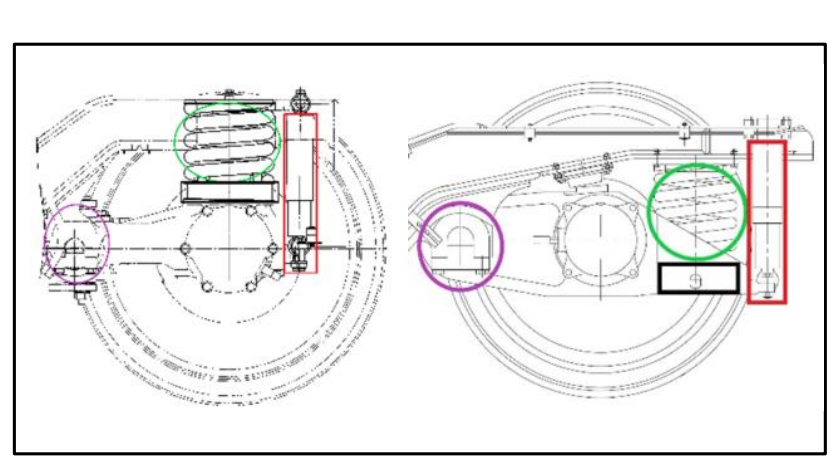

(b)

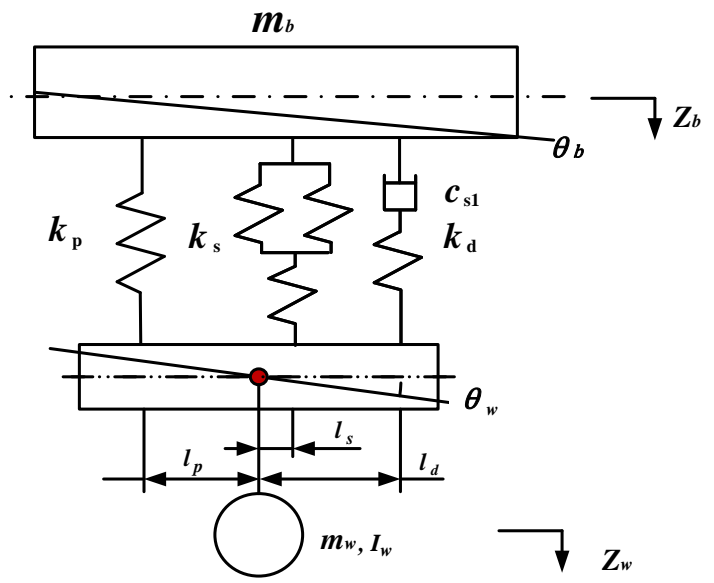

(c)

Figure 11. Vehicle dynamic model with different primary suspensions. (a) Vehicle-track coupled model; (b) overview of primary suspension arrangements; (c) schematic arrangement of primary suspension. 
Table 2. Parameters of coil spring set for side-placed and centrally-placed arrangements

\begin{tabular}{|c|c|c|c|c|}
\hline \multirow[t]{2}{*}{ Parameter } & \multicolumn{2}{|c|}{ Centrally-placed springs } & \multicolumn{2}{|c|}{ Side-placed springs } \\
\hline & Outer & Inner & Outer & Inner \\
\hline Orientation & right & left & right & left \\
\hline Number of active coils $n$ & 3.4 & 6.3 & 4.7 & 7.2 \\
\hline Wire diameter $d(\mathrm{~mm})$ & 39.5 & 25.5 & 31.2 & 21.6 \\
\hline Spring diameter $D(\mathrm{~mm})$ & 206 & 116 & 207.8 & 133.3 \\
\hline Preloaded static height $H_{0}(\mathrm{~mm})$ & 256 & 256 & 289 & 289 \\
\hline Shear modulus $G(\mathrm{GPa})$ & 78.5 & 78.5 & 78.5 & 78.5 \\
\hline Density $\rho\left(\mathrm{kg} / \mathrm{m}^{3}\right)$ & 7950 & 7950 & 7950 & 7950 \\
\hline Poisson's ratio $\lambda$ & 0.3 & 0.3 & 0.3 & 0.3 \\
\hline loss factor $\eta$ & 0.001 & 0.001 & 0.001 & 0.001 \\
\hline Static spring stiffness $k_{s}(\mathrm{kN} / \mathrm{m})$ & 804 & 422 & 220 & 120 \\
\hline $\begin{array}{l}\text { Distance from axle box centre to } \\
\text { coil spring centre, } l_{s}(\mathrm{~m})\end{array}$ & \multicolumn{2}{|c|}{0} & \multicolumn{2}{|c|}{0.27} \\
\hline $\begin{array}{l}\text { Distance from axle box centre to } \\
\text { vertical damper, } l_{d}(\mathrm{~m})\end{array}$ & \multicolumn{2}{|c|}{0.27} & \multicolumn{2}{|c|}{0.475} \\
\hline $\begin{array}{l}\text { Distance from axle box centre to } \\
\text { pivot bushing, } l_{p}(\mathrm{~m})\end{array}$ & \multicolumn{2}{|c|}{0.4} & \multicolumn{2}{|c|}{0.4} \\
\hline
\end{tabular}

Table 3. Vehicle and track parameters

\begin{tabular}{ccc}
\hline Parameters & Value & Description \\
\hline$m_{\mathrm{c}}$ & $22100 \mathrm{~kg}$ & Car body mass (whole vehicle) \\
$m_{\mathrm{b}}$ & $2530 \mathrm{~kg}$ & Bogie mass (whole bogie) \\
$m_{\mathrm{w}}$ & $1800 \mathrm{~kg}$ & Wheelset mass \\
$I_{\mathrm{w}}$ & $9 \mathrm{~kg} \cdot \mathrm{m}^{2}$ & Moment of inertia of radial arm \\
$k_{p \mathrm{z}}$ & $17 \mathrm{MN} / \mathrm{m}$ & Vertical stiffness of radial arm pivot bush \\
$k_{\mathrm{rub}}$ & $7.0 \mathrm{MN} / \mathrm{m}$ & Vertical stiffness of rubber pad \\
$k_{\beta}$ & $8800 \mathrm{~N} \cdot \mathrm{m} / \mathrm{rad}$ & Torsional stiffness of radial arm rubber bushing \\
$c_{\mathrm{s} 1}$ & $5 \mathrm{kN} \cdot \mathrm{s} / \mathrm{m}$ & Vertical damping coefficient of hydraulic damper \\
$k_{d}$ & $50 \mathrm{MN} / \mathrm{m}$ & Vertical stiffness in series with hydraulic damper \\
$k_{\mathrm{s} 2}$ & $0.24 \mathrm{MN} / \mathrm{m}$ & Vertical stiffness of secondary suspension \\
$c_{\mathrm{s} 2}$ & $20 \mathrm{kN} \cdot \mathrm{s} / \mathrm{m}$ & Vertical damping coefficient of secondary suspension \\
$l_{\mathrm{b}}$ & $6.3 \mathrm{~m}$ & Half distance between bogies \\
$l_{\mathrm{w}}$ & $1.15 \mathrm{~m}$ & Bogie half-wheelbase \\
$v$ & $75 \mathrm{~km} / \mathrm{h}$ & Vehicle speed \\
$E I$ & $6.45 \mathrm{MN} \cdot \mathrm{m}^{2}$ & Rail shear modulus \\
$G$ & $0.77 \times 10^{11} \mathrm{~N} / \mathrm{m}^{2}$ & Rail density \\
$\rho$ & $7850 \mathrm{~kg} / \mathrm{m}^{3}$ & Rail cross-section area \\
$A$ & $7.69 \times 10^{-3} \mathrm{~m}^{2}$ & Shear coefficient \\
$\kappa$ & 0.45 & Rail damping loss factor \\
$\eta_{r}$ & 0.01 & Fastener stiffness \\
$k_{\mathrm{f}}$ & $60 \mathrm{MN} / \mathrm{m}$ & Fastener damping loss factor \\
$\eta_{\mathrm{f}}$ & 0.25 & Sleeper spacing \\
$d$ & $0.595 \mathrm{~m}$ & \\
\hline & &
\end{tabular}


The point mobilities of the wheel and rail are shown in Figure 12. The mobility of the leading wheel of the vehicle model is shown for the cases including the dynamic stiffness of the side-placed spring and the centrally-placed spring. There are differences between the two wheel mobilities around the natural frequencies of the spring sets. In the frequency range considered, the track mobility is stiffness-controlled and the wheel mobility is predominantly mass-controlled. The frequency at which the wheel and rail mobility curves intersect can be identified as the so-called P2 resonance frequency [26] of the wheel/rail system at which the wheelset mass bounces on the track stiffness. This frequency depends on the track support stiffness and lies between 50 and $60 \mathrm{~Hz}$ for the current value of $60 \mathrm{MN} / \mathrm{m}$. In the case of the side-placed spring, the $\mathrm{P} 2$ resonance occurs close to the internal resonances of the coil springs.
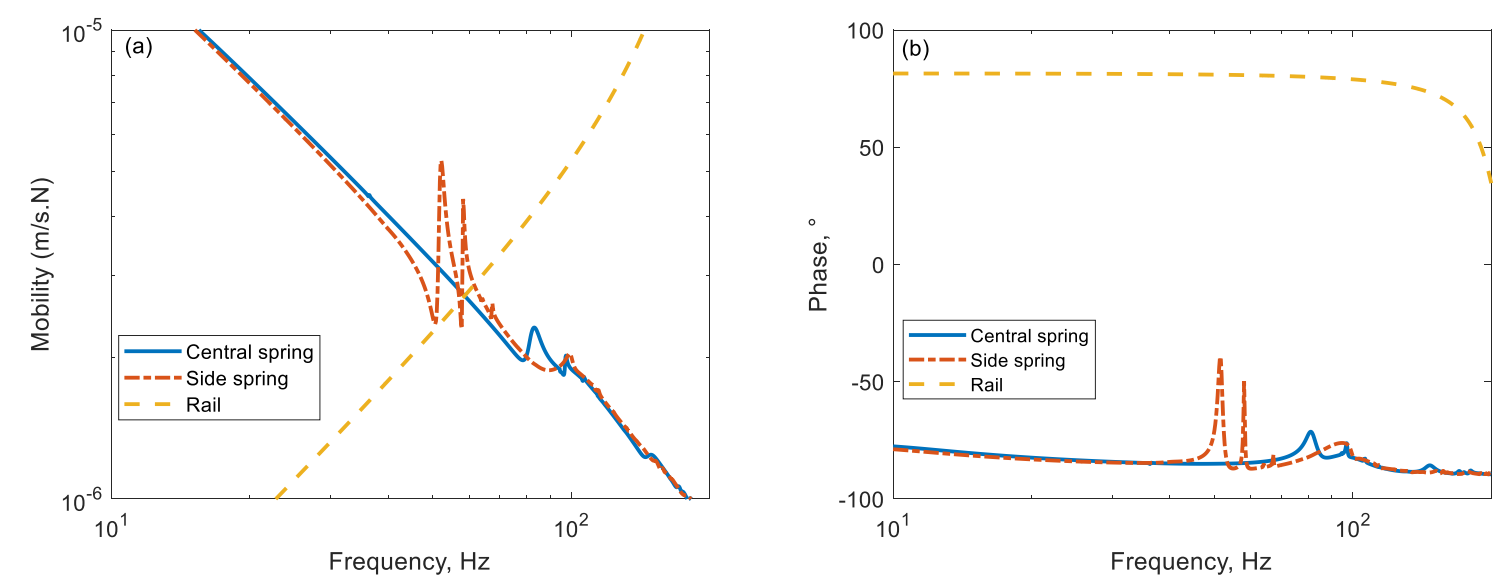

Figure 12. Mobility magnitude and phase of rail and wheel for different models. (a) Mobility magnitude; (b) phase.

\subsection{The influence on vehicle-track dynamic responses}

The responses of the leading wheel are shown in Figure 13(a) for the vehicle models with central and side-placed spring set. These results are given in the form of vibration transmissibilities from the roughness, i.e. vibration displacement for a unit roughness. The wheel responses have peaks at the corresponding P2 resonance frequency, as identified from Figure 12; that is because the wheel/rail contact force reaches a maximum at this frequency. Due to the inclusion of the dynamic properties of the springs, peaks and dips occur in the wheel responses; these occur at or close to the natural frequencies of the spring set. These features are more pronounced for the side-placed spring than for the central spring, as seen previously in the mobility in Figure 12, because the natural frequencies are lower in this case. Figure 13(b) shows the ratio between the wheel response obtained using the model with the dynamic spring model relative to that for the model with the static stiffness. The minima in the wheel response 
occur at 51.9 and $58.2 \mathrm{~Hz}$, which correspond to the fixed-fixed natural frequencies of the spring set.
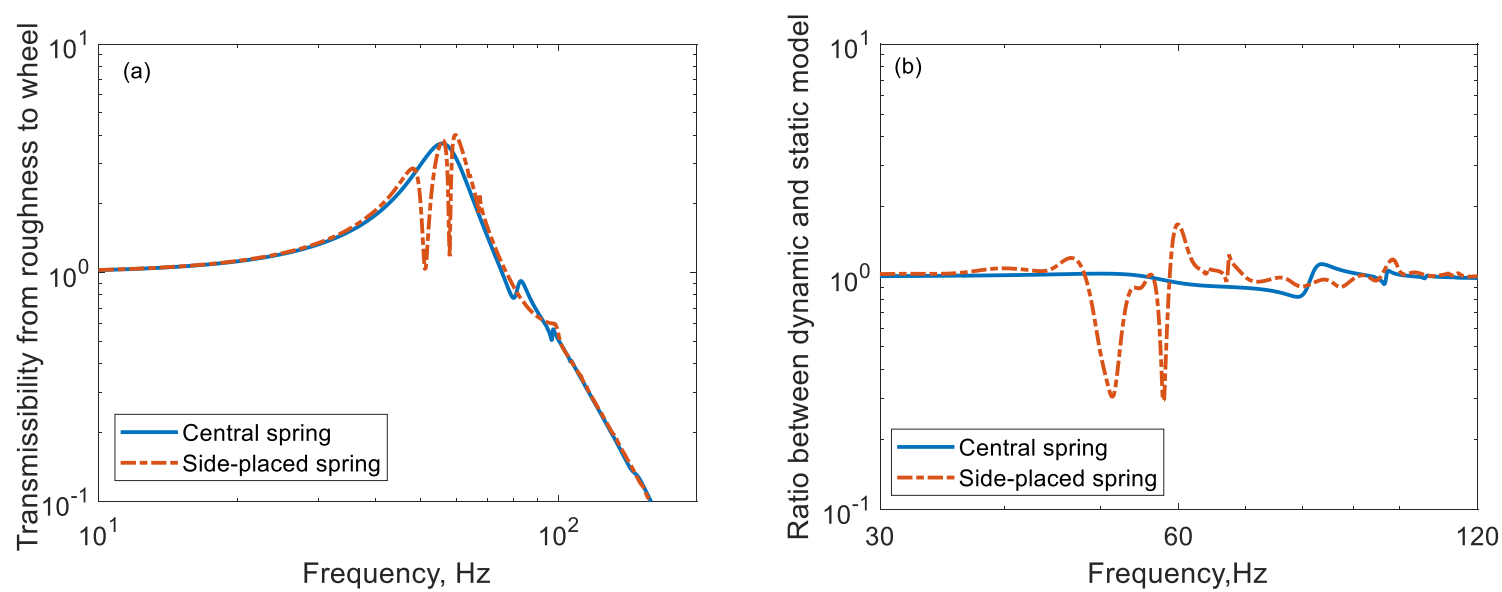

Figure 13. Wheel response for different models. (a) Transmissibility from roughness to wheel of dynamic stiffness models; (b) the response ratio of wheel between dynamic and static stiffness model.

The responses of the rail at the position of this wheel are shown in Figure 14(a). Results are again shown for the two suspension arrangements. The rail responses have broad peaks at the $\mathrm{P} 2$ resonance frequency, similar to the result for the wheels above. Figure 14(b) shows the ratio between the responses of the dynamic and static stiffness models. As above, it can be seen that dips occur at the frequencies corresponding to the spring set natural frequencies. The influence of the side-placed spring set is much more than that of the central spring set due to its lower resonance frequencies.
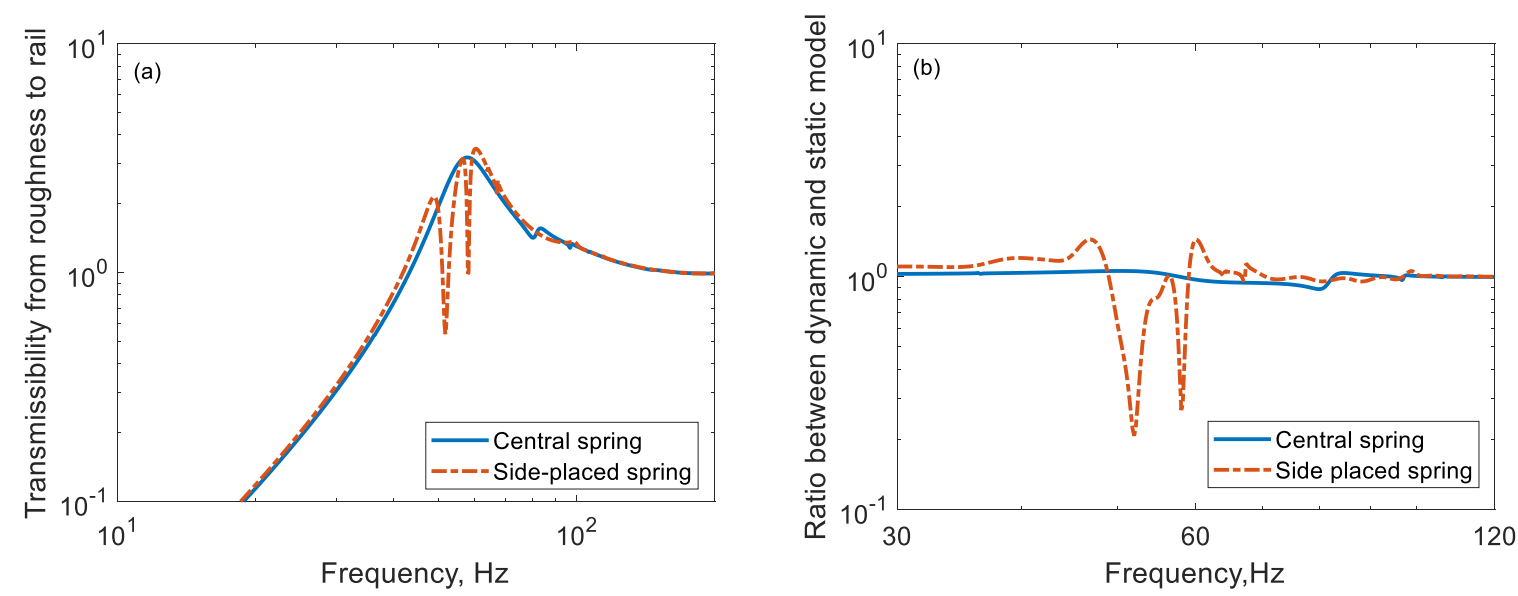

Figure 14. Rail response for different models. (a) Transmissibility from roughness to rail of dynamic stiffness models; (b) the response ratio of rail between dynamic and static stiffness model. 
Figure 15 shows the vibration of the leading bogie at the mid-point between the two wheelsets for the side-placed spring model. Due to the time delay between the different wheels passing over a point on the track, there are dips in the response when the two wheels are in anti-phase and broad peaks when they are in phase. These peaks and dips shift in frequency as the train speed varies so it is instructive to consider the envelope of the response, which corresponds to the result with no time delay. This is also shown in Figure 15.

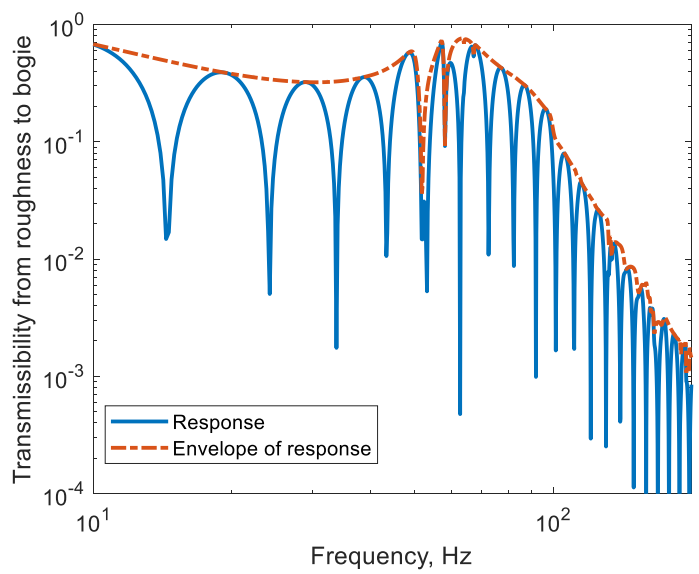

Figure 15. Response at the centre of the leading bogie for the side-placed spring model with phase lag between different wheels on the track at speed $75 \mathrm{~km} / \mathrm{h}$ and corresponding response envelope.

Figure 16(a) shows the envelope of the transmissibility from the roughness to the centre of the bogie frame for both models. The transmissibilities decrease sharply around the spring set natural frequencies for both models. The ratios of the bogie frame responses between dynamic and static stiffness models of the coil springs are shown in Figure 16(b). This again shows the dips at the spring set natural frequencies. 

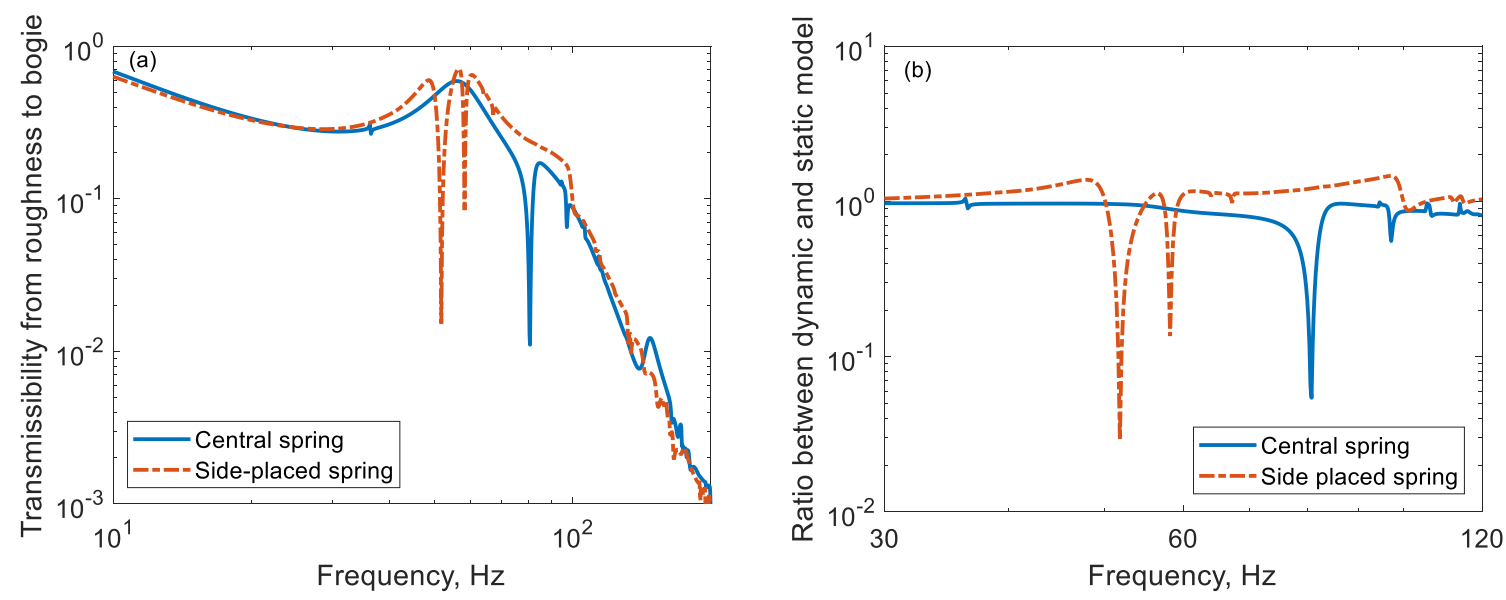

Figure 16. Bogie response for different models. (a) Transmissibility from roughness to bogie of dynamic stiffness models (based on response envelope); (b) the response ratio of bogie between dynamic and static stiffness model.

\subsection{Comparison with measurements}

Measurements of vibration on the axle box and the bogie frame of a metro vehicle with side-placed springs are used to verify the calculations from the dynamic model. The parameters in Tables 2 and 3 were chosen to correspond to this vehicle. The measurement was taken at a running speed of around $75 \mathrm{~km} / \mathrm{h}$. The track unevenness is unknown so it is only possible to make a qualitative comparison with the results from the model. Figure 17 shows the calculated and measured vibration power spectral density (PSD) of the vehicle. Vibration is shown on the axle box and on the bogie frame at a position midway between the two wheelsets. Despite the fact that the unevenness spectrum is unknown, and the model neglects the flexibility of the wheelset and bogie frame, quite good agreement is seen between the measurements and predictions. Clear dips are seen in the response of both the axle box and the bogie frame at the natural frequencies of the spring set between 50 and $60 \mathrm{~Hz}$. In addition, peaks can be seen in the measured axle box vibration at multiples of $8 \mathrm{~Hz}$, which corresponds to the wheel rotation frequency at this speed. These are caused by out-of-roundness of the wheels, which have a radius of $0.42 \mathrm{~m}$; this is not taken into account in the model.

In these results, the axle box response has a dip at the spring set natural frequencies in both the measurements and predictions. The bogie vibration also has a dip, although it is larger in the prediction than the measurement (partly because a finer frequency resolution is used). These results confirm the behaviour described by the model in which there is no amplification associated with the spring natural frequencies. 

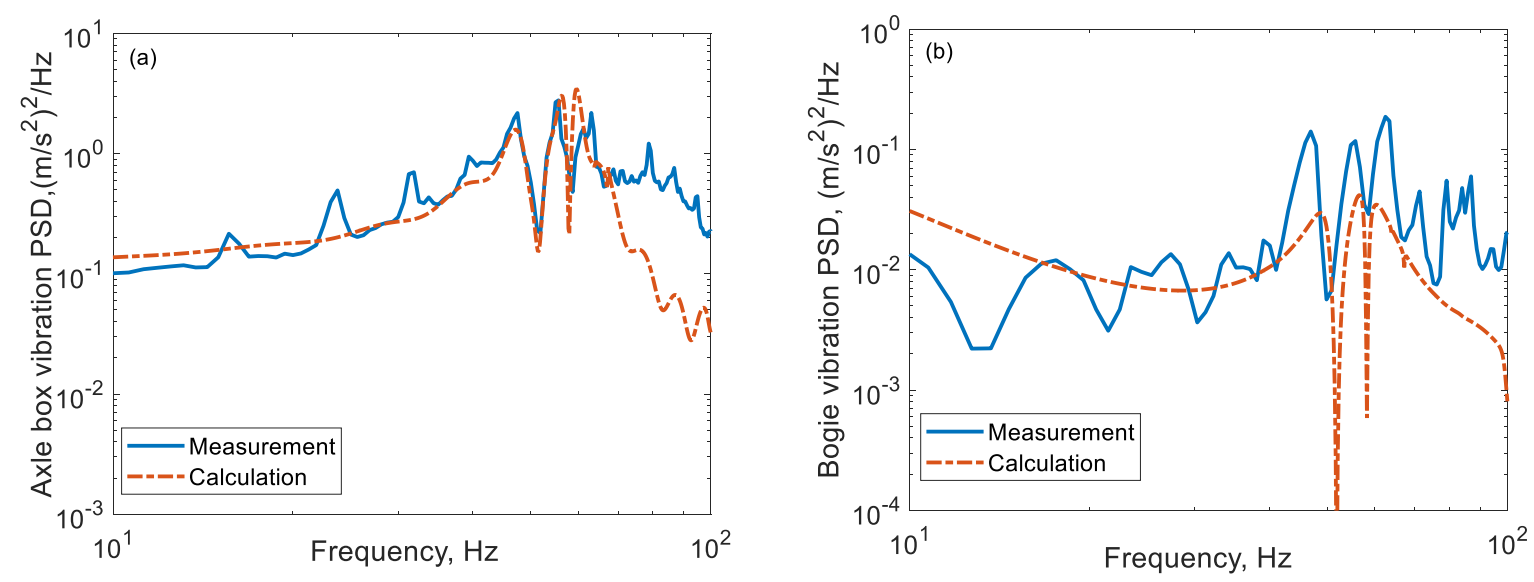

Figure 17. Comparison between calculated and measured vibration PSD of vehicle with sideplaced spring set on slab track with fastener stiffness $60 \mathrm{MN} / \mathrm{m}$. (a) Axle box; (b) bogie frame (calculated results based on response envelope).

\section{Conclusions}

A mechanism has been identified by which dynamic amplification in the vibration transmission caused by the internal resonances of isolators can be minimised. This is based on a pivot arm with a flexible pivot bushing. The presence of a rotational resonance of the pivot arm causes the forces transmitted through the pivot bushing to be out of phase with the force transmitted through the main spring above a certain frequency. Selection of appropriate parameter values for the pivot arm moment of inertia and pivot bushing stiffness can lead to these two forces having similar magnitudes and therefore cancellation occurs in the total transmitted force. The total force, and therefore the response of the suspended mass, can have a minimum at the spring natural frequency instead of a peak. Nevertheless, some amplification in the transmission can occur at other frequencies. Moreover, the response of the isolator itself at its internal resonance is not attenuated so this mechanism is not suitable for mitigating against fatigue failure of the springs.

Through predictions and measurements, it has been shown that this mechanism occurs in practice in the response of a metro rail vehicle with metal coil springs in the primary suspension. For the designs of vehicle considered, the forces transmitted through the coil spring set and the pivot bushing largely cancel with each other at the spring natural frequency, thus avoiding a peak in the transmitted vibration. 


\section{Acknowledgement}

This work was carried out while the first author was an academic visitor at ISVR, University of Southampton, sponsored by the CSC Program of China. All data published in this paper are openly available from the University of Southampton repository at https://doi.org/10.5258/SOTON/D1188.

\section{References}

[1] M. Harrison, A.O. Sykes, M. Martin, Wave effects in isolation mounts. J. Acoust. Soc. Am. 24 (1952) 62-71.

[2] Y. Du, R. A. Burdisso, E. Nikolaidis, D. Tiwari. Effects of isolators internal resonances on force transmissibility and radiated noise. J. Sound Vib. 268(2003): 751-778.

[3] Y. Du, R.A. Burdisso, E. Nikolaidis. Control of internal resonances in vibration isolators using passive and hybrid dynamic vibration absorbers. J. Sound Vib. 286 (2005) 697727.

[4] A. O. Sykes. Isolation of vibration when machine and foundation are resilient and when wave effects occur in the mount. Noise Control 6 (3) (1960), 23-38.

[5] E.E. Ungar, C.W. Dietrich. High-frequency vibration isolation. J. Sound Vib. 4 (1966) 224-241.

[6] B.Yan, M.J. Brennan, S.J. Elliott, N.S. Ferguson. Characteristics of distributed parameter isolators. J. Sound Vib. 320 (2009) 516-526.

[7] H. Douville, P. Masson, A. Berry. On-resonance transmissibility methodology for quantifying the structure-borne road noise of an automotive suspension assembly. Appl. Acoust. 67 (2006) 358-382.

[8] P.G. Dylejko, I.R. Macgillivray, S.M. Moore, A.T. Skvortsov, The Influence of Internal Resonances from Machinery Mounts on Radiated Noise from Ships, IEEE J. Ocean. Eng. 42 (2016) 399-409.

[9] W. Wang, Research on Mechanism of fatigue crack of high speed train axle box spring. Tiedao Xuebao/Journal China Railw. Soc. 37 (6) (2015) 41-47.

[10] W. Sun, D.J. Thompson, J. Zhou. The influence of vehicle-track dynamic coupling on the fatigue failure of coil springs within the primary suspension of metro vehicles. Veh. Syst. Dyn. (2019) https://doi.org/10.1080/00423114.2019.1643486.

[11] B. Yan, M.J. Brennan, S.J. Elliott, et al. Active vibration isolation of a system with a distributed parameter isolator using absolute velocity feedback control. J. Sound Vib. 10 (2010) 1601-1614.

[12] P. G. Dylejko, I.R. MacGillivray. On the concept of a transmission absorber to suppress internal resonance. J. Sound Vib. 333 (2014) 2719-2734.

[13] K. Michalczyk. Dynamic stresses in helical springs locally coated with highly-damping material in resonant longitudinal vibration conditions. Int. J. Mech. Sci. 90 (2015) 53-60. 
[14] J. Zhou, R. Goodall, L. Ren, H. Zhang, Influences of car body vertical flexibility on ride quality of passenger railway vehicles. Proc. Inst. Mech. Eng. Part F, J. Rail Rapid Transit. 223 (2009) 461-471.

[15] D. Thompson. Railway Noise and Vibration: Mechanisms, Modelling and Means of Control. Elsevier: Oxford (2008).

[16] S.D. Iwnicki, S. Stichel, A. Orlova, M. Hecht. Dynamics of railway freight vehicles. Veh. Syst. Dyn. 53 (2015) 995-1033.

[17] S. Bruni, J. Vinolas, M. Berg, O. Polach, S. Stichel. Modelling of suspension components in a rail vehicle dynamics context. Veh. Syst. Dyn. 49 (2011) 1021-1072.

[18] W. Sun, D.J. Thompson, J. Zhou, Dao Gong. Analysis of dynamic stiffness effect of primary suspension helical springs on railway vehicle vibration. J. Phys. Conf. Series. 744 (2016) 012149.

[19] S. Iwnicki. Handbook of Railway Vehicle Dynamics. CRC Press, 2006.

[20] Z. He, S. Luo, W. Ma. Influence of primary suspension system to dynamic performance of high-speed EMU. In Int. Conf. on Transp. Eng. 2009 3502-3507.

[21] J. Lee, D.J. Thompson. Dynamic stiffness formulation, free vibration and wave motion of helical springs. J. Sound Vib. 239 (2001) 297-320.

[22] J.M. Renno, B.R. Mace. Vibration modelling of helical springs with non-uniform ends. J. Sound Vib. 331 (2012) 2809-2823.

[23] P. Gardonio, M.J. Brennan, Mobility and impedance methods in structural dynamics, chapter 9 in F. Fahy and J. Walker (eds) Advanced applications of acoustics, noise and vibration. E\&FN Spon: London (2004).

[24] W. Sun, J. Zhou, D.J. Thompson, D. Gong. Vertical random vibration analysis of vehicletrack coupled system using Green's function method. Veh. Syst. Dyn. 52 (2014) 362-389.

[25] V.K. Garg and R.V. Dukkipati. Dynamics of Railway Vehicle Systems. Academic Press: New York (1984).

[26] K.L. Knothe and S.L. Grassie. Modelling of railway track and vehicle/track interaction at high frequencies. Veh. Syst. Dyn. 22 (1993) 209-262. 